\title{
運動量理論に基づくディーゼル噴霧の周囲流体導入過程に関する一考察
}

\author{
川那辺 洋*1, 石山 拓二*1, 塩路 昌宏 ${ }^{* 2}$
}

\section{A study of entrainment process in diesel spray based on the momentum theory}

\author{
Hiroshi KAWANABE $^{* 1}$, Takuji ISHIYAMA ${ }^{* 1}$ and Masahiro SHIOJI ${ }^{* 2}$ \\ ${ }^{{ }^{*},{ }^{*} 2}$ Kyoto University. School of Energy Science \\ Yoshida Hon-machi, Sakyo-ku, Kyoto 606-8501, Japan
}

Received: 29 June 2017; Revised: 21 August 2017; Accepted: 16 November 2017

\begin{abstract}
Entrainment process of surrounding fluid for a diesel spray is investigated based on the momentum theory and 1-D simple spray model developed by Musculus et. al. Entrained fluid distribution along the spray axis is theoretically estimated. The results show that the absolute value of entrainment velocity depends on axis location and is inversely proportional to the distance from the nozzle. Therefore, the large amount of entrained fluid comes from the upstream region near field of nozzle. 1-D simple spray model is performed for the same target and the effect of the injection rate on entraining process is clarified.
\end{abstract}

Keywords : Diesel spray, Entrainment process, Spray development, Momentum theory

\section{1. ま え がき}

近年，ディーゼルエンジンでは高効率，低エミッションを目指して細やかな燃焼制御が要求されている。これ には，噴射系と燃焼室形状のマッチングに加えて，運転条件に合わせて噴射タイミング，量，分割数等を幅広く かつ精度良く設定する必要がある。これは，燃焼する際の混合気特性を変化させることに対応しており，燃料を 噴射した際に噴霧内に導入される周囲流体の状況を詳細に検討寸ることが重要である.

これまで，噴霧への周囲気体導入および混合気形成については数多くの理論的および実験的手法を用いて検討 がなされてきた．例えば，和栗らはガス噴流における運動量理論をディーゼル噴霧に適用寸るとともに，燃料を 噴射することにより形成される噴霧の非定常な発達, 混合気形成過程を理論的に明らかにした(和栗他, 1959). 廣 安らは噴霧先端到達距離および噴霧角を実験的に求め, 噴射および周囲気体条件の影響を明らかにした(廣安他, 1978). Fujimoto らは噴霧観察よりエントレインされる空気流動および多噴孔噴霧間の空気がエントレインされる 様子を詳細に調べている(Fujimoto et al., 1981). さらに近年では, 冬頭らは噴霧可視化および運動量理論に基づき, 噴霧周囲気体の容積に制限がある場合のエントレインメント過程を明らかにしている(冬頭他, 2014). また, Musculus および Kattke は 1 次元噴霧モデルに基づき，噴射率が噴霧発達に及ぼす影響を明らかにするとともに， 噴射終了後の噴霧発達およびエントレインメント過程について詳細に検討し，噴射終了時に局所的にエントレイ ンメント量が増えることを示した(Musculus and Kattke, 2009). ここで, 例えば筒内に EGR ガスが偏って分布する 等の不均一があれば, 形成される混合気特性においてどのような性状の周囲流体が導入されるかが重要となる. しかし，噴霧のどの部分からどの領域の周囲気体が噴霧内部へ導入されるのかということに関する知見は十分で

\footnotetext{
No.17-00294 [DOI:10.1299/transjsme.17-00294], J-STAGE Advance Publication date : 29 November, 2017

*1 正員, フェロー, 京都大学大学院エネルギー科学研究科（†606-8501 京都府京都市左京区吉田本町）

*2 正員, 名誉員, フェロー, 京都大学大学院エネルギー科学研究科

E-mail of corresponding author: kawanabe@energy.kyoto-u.ac.jp
} 


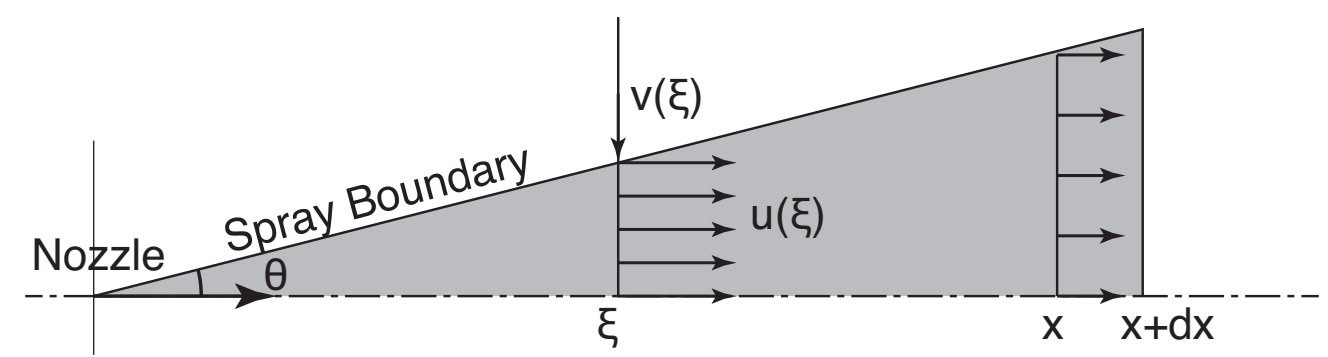

Fig. 1 Schematic of developing process model for the spray. Spray cone angel assumed to be a constant value of $\theta$. The direction of entrainment velocity $v(\xi)$ is perpendicular to the spray axis.

はなく，理論的に検討された例も少ない。

そこで本研究では，まず和栗らの用いた運動量理論(1)に基づき，非定常に発達するディーゼル噴霧の側面より 導入される空気量およびその範囲を見積もる方法を提案する. さらに, Musculus および Kattke の 1 次元噴霧発達 モデル(Musculus and Kattke, 2009)に基づきエントレインメント過程に及ぼす噴射率の影響を明らかにする.

\section{2. 運動量理論に基づくエントレインメント解析}

ここでは, 和栗らの運動量理論に基づき(和栗他, 1959), 発達するディーゼル噴霧が導入する周囲流体の範囲に ついて検討する. 寸なわち, 噴霧発達に伴い噴霧内部に導入される周囲流体の速度がすべて軸に対して垂直の成 分のみを持つと仮定し，側面における速度分布を見積もる.

図 1 は円錐状に発達する噴霧を模式的に示したものであり，噴霧角を $2 \theta$ と仮定する．さらに噴射する燃料の 体積に比べてエントレインされる周囲気体の体積が十分に大きいとすると, 噴霧先端が $x$ から $x+d x$ に変化す る際に導入される周囲気体の体積 $d V$ は

$$
d V=\pi x^{2} \tan ^{2} \theta \cdot d x
$$

となる.ここで噴霧先端距離 $x$ については運動量理論により以下のように噴射開始からの時間 $t$ および噴霧角 $\theta$ の平方根に反比例する.

$$
x=K \sqrt{\frac{1}{\tan \theta}} \sqrt{t}
$$

ただし，ここで $K$ は周囲気体，燃料の密度およびノズル径，噴射速度の関数である. 式(2)を時間で微分すると ともに式(2)を用いて $t$ を消去すると以下のようになる.

$$
\frac{d x}{d t}=K \sqrt{\frac{1}{\tan \theta}} \frac{1}{2 \sqrt{t}}=\frac{K^{2}}{2 \tan \theta} \frac{1}{x}
$$

式(3)を式(1)に代入すると体積の増加率は式(4)のように求まる.

$$
d V=\frac{\pi}{2} K^{2} x \tan \theta \cdot d t
$$

一方, 噴霧側面より導入される周囲気体について $x=\xi$ の位置でのエントレインメント速度 $v(\xi)$ として, そ の值を一周積分し, さらにノズル位置から噴霧先端 $x$ まで積分寸ることにより, 噴霧が $x$ まで発達した際の単位 
時間あたりのエントレインメント量が求まる。さらに，これは式(4)の体積増加率に等しいと考えられ，この関係 を用いて $v(\xi)$ を求める.

まず， $v(\xi)$ はその位置における噴霧速度 $u(\xi)$ に比例するとし，比例係数を $\alpha$ とすると $v(\xi)$ は式(3)を用いて 以下のようになる.

$$
v(\xi)=\frac{\alpha K^{2}}{2 \tan \theta} \frac{1}{\xi}
$$

さらに, 先端が $x$ まで発達した噴霧が $d t$ あたりにエントレインする周囲流体の流量 $d Q$ は以下の様に表される.

$$
d Q=\int_{0}^{x} 2 \pi \xi \tan \theta \cdot v(\xi) d \xi \cdot d t=\alpha \pi K^{2} x \cdot d t
$$

式(4)で求めた $d V$ と式(6)の $d Q$ が等しいと仮定すると $\alpha$ は以下の様に求まる.

$$
\alpha=\frac{\tan \theta}{2}
$$

これを式(5)に代入すると，

$$
v(\xi)=\frac{K^{2}}{4} \frac{1}{\xi}
$$

すなわち, 噴霧側面からエントレインされる流体の速度は, そのエントレインされる位置 $\xi$ だけの関数になるこ とが分かる.さらに，噴霧が $x=x_{0}$ まで発達した際に， $\xi$ の位置においてエントレインされた周囲流体の範囲を その位置における等価円を用いて表す。まず噴霧が $x_{0}(>\xi)$ まで発達したときの $\xi$ の位置におけるエントレイ ンメント量は，式 (6) と同様に,

$$
\int_{t_{x=\xi}}^{t_{x=x_{0}}} 2 \pi \xi \tan \theta \cdot v(\xi) d t \cdot d \xi=\int_{t_{x=\xi}}^{t_{x=x_{0}}} \frac{\pi K^{2} \tan \theta}{2} d t \cdot d \xi
$$

ここで，式(3)を用いて $t$ から $x$ の積分に変換すると式(9)は，

$$
\int_{\xi}^{x_{0}} \pi \tan ^{2} \theta x d x \cdot d \xi=\frac{\pi \tan ^{2} \theta}{2}\left(x_{0}^{2}-\xi^{2}\right) \cdot d \xi
$$

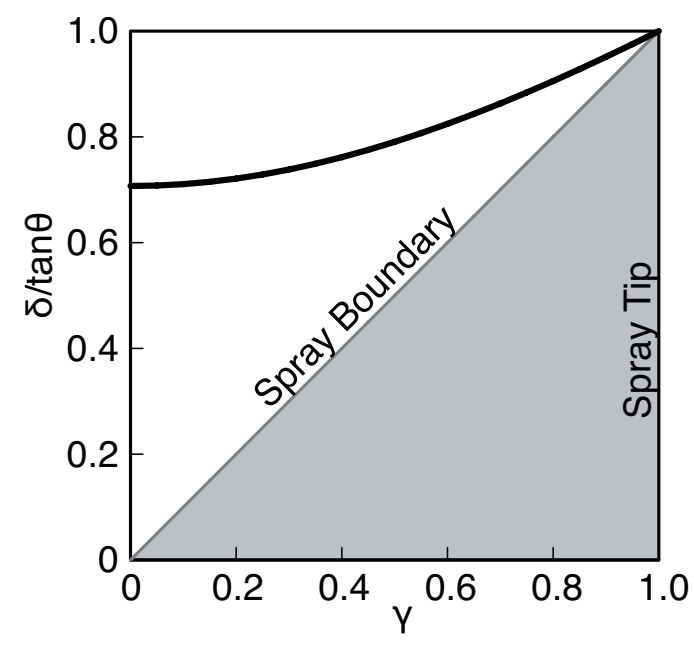

Fig. 2 Entrained fluid area around spray region. The entrained fluid area depends on the spray penetration and spray cone angel. Spray entrained the surround fluid mainly upstream region. 
一方，エントレインされた周囲流体の領域の等価円半径を $r$ とすると，式(10)は以下の式(11)に等しい.

$$
\left\{\pi r^{2}-\pi \xi^{2} \tan ^{2} \theta\right\} \cdot d \xi
$$

ここで， $\xi$ おび $r$ を $x_{0}$ で無次元化しそれぞれ $\gamma, \delta$ とし， $\delta$ をの関数として書くと，

$$
\frac{\delta}{\tan \theta}=\sqrt{\frac{1+\gamma^{2}}{2}}
$$

となる. 図 2 は $\gamma$ に対する $\delta / \tan \theta$ の変化であり, グレーでハッチングされた領域は噴霧内部を表している. こ れによると噴霧最上流部 $(\gamma=0)$ において $\delta / \tan \theta$ は $\sqrt{1 / 2}$ であり, 噴霧先端のおおよそ $70 \%$ 程度の半径にある 周囲気体がエントレインされることが分かる.

\section{3. 一次元噴霧モデルに基づくエントレインメント解析}

前章では，噴霧の発達は準定常を仮定しているので，噴射率，噴射終了後の影響等について検討できない，そ こで，本章では，Musculus らの一次元噴霧モデルに基づく計算手法(Musculus and Kattke, 2009)によりエントレイ ンメント過程について検討する. このモデルでは, 図 3 に示すように噴霧を軸対象と仮定するとともに, 各断面 における半径方向速度・燃料濃度分布について相似性を仮定し, 軸方向を微小要素に分割して, 時間進展を計算 するものである.

このモデルに基づき, 噴霧発達過程およびエントレインメント過程を計算する。 ここでは, 計算条件として噴 射圧力 $160 \mathrm{MPa}$ で噴孔径 $0.123 \mathrm{~mm}$ とし, 雰囲気圧力 $4 \mathrm{MPa}$, 温度 $900 \mathrm{~K}$ の空気中へ $4 \mathrm{mg}$ の軽油を噴射した際 の噴霧発達過程とする．なお，噴射率が立ち上がり，一定および立ち下がりからなる標準条件(STD)における噴 射率は実測に基づき定めるとともに，噴射率が噴射期間の途中で変化する場合についても検討する．図 4 は噴霧 の先端到達距離 $x_{\mathrm{tip}}$ およびエントレインメント率 $m_{\mathrm{e}}$ の時間変化でありノズル出口速度 $u_{0}$ と併せて示す. なお, 噴射率については STD に加えて, 噴射率を 2 段階で上昇させるいわゆるブーツ形(Boot)および 2 段階で低下させ る逆ブーツ形(inv Boot)に変更した際の結果についても検討寸る．ここで，最大噴射率は STD と同じ值になるよ うに設定し，低い側の噴射率は最大噴射率の $1 / 2$ とする。 STD における噴射終了時刻 $t_{\mathrm{s}}$ は $1.44 \mathrm{~ms}$ であり， Boot および inv Boot については STD に噴射量が一致するように設定したために $t_{\mathrm{s}}=1.79 \mathrm{~ms}$ となる. また，エ ントレインメント率 $m_{\mathrm{e}}$ とはその時刻において単位時間あたりに噴霧側面より噴霧内部に導入される周囲流体の 質量を表す。これによると，STDの $x_{\text {tip }}$ は噴射率の立ち上がりに対応した時間に比例する領域とその後の時間の 0.5 乗に比例する領域が見られる. また， $m_{\mathrm{e}}$ については $t_{\mathrm{s}}$ のおおよそ 2 倍の時間まで上昇し，その後下降するこ とが分かる. これらは Musculus らも指摘している噴射終了後に導入率が局所的に上昇し，それが時間とともに 下流に移動する，いわゆる「Entrainment Wave」によるために生じる，また，Boot では初期の噴霧発達が抑制さ れるために, $m_{\mathrm{e}}$ も小さいが，その後 $t_{\mathrm{s}}$ のおおよそ 2 倍の時刻において最大となる. しかし，その值は STDに比 べてやや小さい.一方, inv Boot では初期の噴霧発達は STD とほぼ同様であるのに対して, $m_{\mathrm{e}}$ は早くに最大と なったのちに低下し, 最大值も STD に比べてかなり小さな值となることが分かる. これは, inv Boot では $t=$ $0.9 \mathrm{~ms}$ 付近で噴射率の值が半分に低下し，この減少に対応して $m_{\mathrm{e}}$ が最大となる時期が決まるためである.

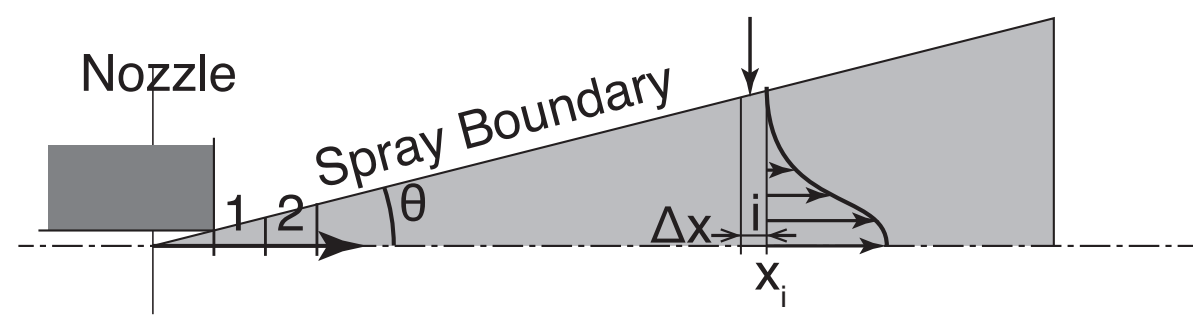

Fig. 3 Schematic of 1-D model for spray developing process. Spray cone angle is fixed to be $\theta$.

Radial distribution of velocity is assumed to be self-similar 


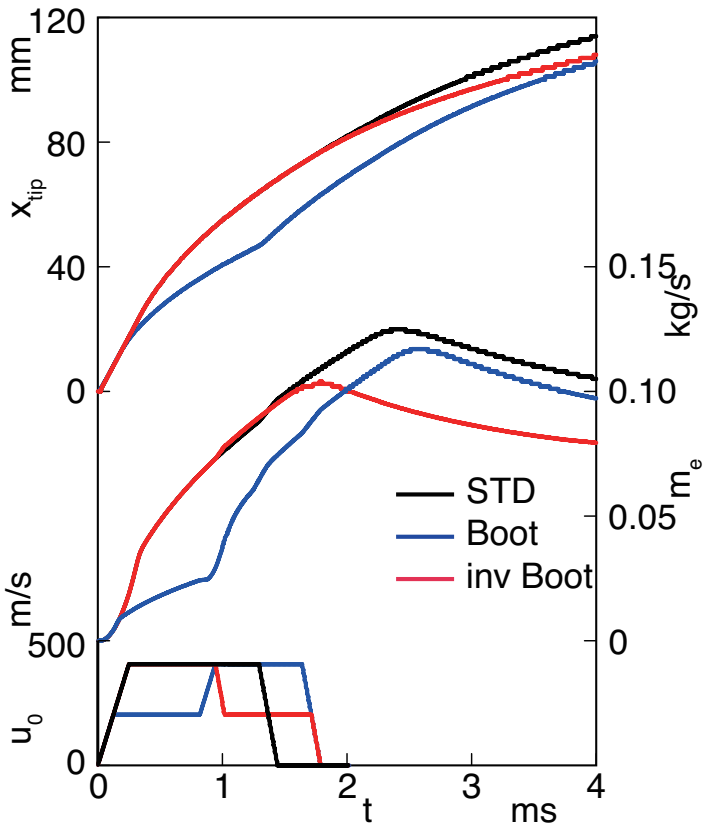

Fig. 4 Temporal changes of spray tip penetration $x_{\text {tip }}$ and entrainment-mass rate $m_{\mathrm{e}}$ with nozzle velocity $u_{0}$. Three types of injection rate were calculated. $m_{\mathrm{e}}$ of "inv Boot" (red) becomes lower than that of "STD"(black), especially early stage of injection.

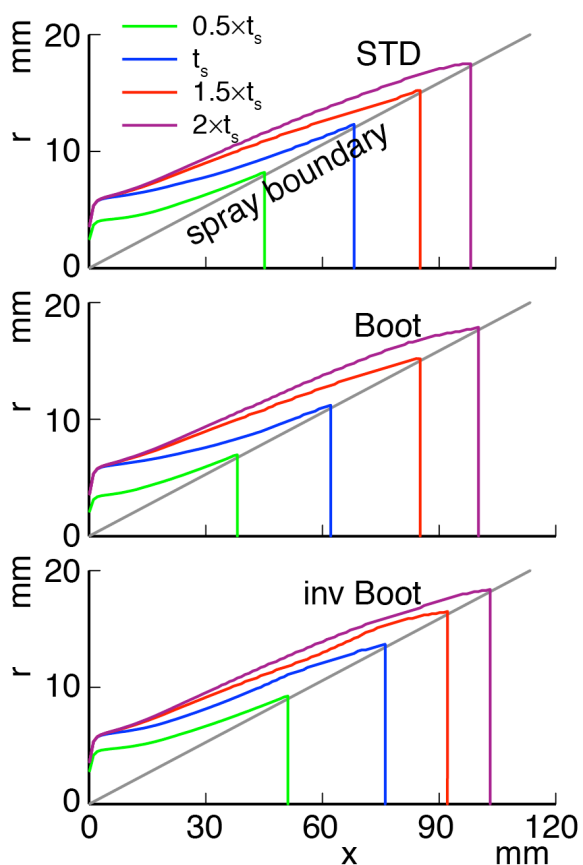

Fig. 5 Temporal changes of entrained fluid area around spray region. Injection rate shape does not much affect entrained fluid area after end of the injection timing

これらの条件において, エントレインされた周囲気体の等価半径 $r$ を前章と同様に求める. 図 5 はその結果であ

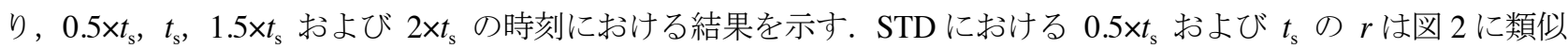
した分布となるが，ノズルすぐ下流における值が噴霧先端部の半径のおおよそ半分程度であり，運動量理論に基 づく結果に比べてやや小さいことが分かる。これは噴射率の立ち上がり期間においてエントレインメント率が低 下寸ることに加えて, 噴霧内部において燃料および周囲気体のいずれも考慮しているために相対的にエントレイ ンメント率が低下寸るためである。一方, 噴霧先端部ではエントレインされる周囲流体の範囲が図 2 の結果に比 べてやや大きいことが分かる.これは噴射率立ち上がりの影響を受けるためである.さらに, 時間のたった $1.5 \times t_{\mathrm{s}}$ および $2 \times t_{\mathrm{s}}$ では，ノズルすぐ下流の值はほぼ同様であるが，下流で $r$ が大きくなることが分かる。これは

「Entrainment Wave」が下流に移動していくためである。つぎに，Boot および inv Bootの条件においても噴射終 わりまでの期間については STD とほぼ同様にエントレインメント過程は $x_{\text {tip }}$ の位置に対応したものとなり, 噴 射終了後について STD とほぼ同様である.これらのことから, 噴射終了後に十分時間がたったときの, 噴霧周り の周囲気体の導入分布については噴射率の影響を大きくは受けないことが分かる.

\section{4. ま と め}

以上，運動量理論に基づき，非定常に発達するディーゼル噴霧の側面より導入される空気量を見積もる方法を 提案するとともに，エントレインメントにより導入される周囲気体の範囲を理論的に示した. これにより以下の ことが明らかになった。

（1）噴霧側面のある位置よりエントレインされる周囲流体の速度の大きさはその位置のノズルからの距離のみで 決まり，距離に反比例する.

（2）噴霧上流部においてエントレインされる周囲流体の範囲は，その噴霧の先端の半径の $1 / \sqrt{2}$ となる. 
さらに, Musculus らの 1 次元噴霧モデルに基づき, 噴射率が非定常に変化する場合におけるエントレインメン 卜過程を計算することにより, 実際のディーゼル噴霧に近い条件における噴霧に導入される周囲気体の範囲を明 らかにした。これにより, 以下のことが明らかになった。

(3) エントレインされる周囲流体の範囲は運動量理論で推定される領域と同様であるが，ノズル寸ぐ下流の範囲 が噴霧先端部の半径の約半分であり，運動量理論で推定される值よりも小さい.

(4) 噴霧先端部周辺においてエントレインされる周囲流体の範囲は, 運動量理論により求めた範囲よりやや大き い.これは，噴射率の立ち上がりの影響を受けるためである.

(5) 噴射終了後に十分時間がたったときの噴霧周りの周囲気体の導入分布については噴射率の影響を大きくは受 けない。

これら得られた結果を用いれば，例えば噴霧内部に積極的に EGR ガスを導入するための EGR ガス配置や，燃 焼室形状および噴霧角と噴孔数の最適值を理論的に検討できる可能性がある.

なお，本研究は総合科学技術・イノベーション会議の SIP(戦略的イノベーション創造プログラム)「革新的燃 焼技術」(管理法人:JST) によって実施された。ここに記して謝意を表す.

\section{文献}

Fujimoto, H., Sugihara, H., Tanabe, H. and Sato, G. T., Investigation on combustion in medium-speed marine diesel engines using model chambers, Proc. of $14^{\text {th }}$ Int. Congress on Combustion Engines CIMAC (1981), pp. D38-1-D38-27.

冬頭孝之, 服部義昭, 山下勇人, 増田誠, 多噴孔ノズルからの高圧噴射ディーゼル噴霧火炎の set-off 長の支配要 因, 第 25 回内燃機関シンポジウム, No. 50 (2014).

廣安博之, 角田敏一, 田坂真一, ディーゼル噴霧の到達距離に関する研究, 日本機械学会論文集, Vol. 44, No. 385 (1978), pp. 3208-3219.

Musculus, M.P.B. and Kattke, K., Entrainment waves in diesel jets, SAE Paper No. 2009-01-1355 (2009).

和栗雄太郎, 藤井勝, 網谷竜夫, 恒屋礼二郎, ディーゼル機関燃料噴霧の到達距離に関する研究, 日本機械学会 論文集，Vol. 25, No. 156 (1959), pp. 820-826.

\section{References}

Fujimoto, H, Sugihara, H., Tanabe, H. and Sato, G. T., Investigation on combustion in medium-speed marine diesel engines Using Model Chambers, Proc. of $14^{\text {th }}$ Int. Congress on Combustion Engines CIMAC (1981), pp. D38-1-D38-27.

Fuyuto, T., Hattori, Y., Yamashita, H. and Masuda, M., A dominant factor on set-off length of high pressure diesel spray flame from multi-hole nozzle, Proceedings of $25^{\text {th }}$ Internal Combustion Engine Symposium, No. 50 (2014) (in Japanese).

Hiroyasu, H., Kadota, T. and Tasaka, S., Diesel funmu no toutatsu kyori ni kansuru kenkyu, Transactions of the Japan Society of Mechanical Engineers, Vol. 44, No. 385 (1978), pp. 3208-3219 (in Japanese).

Musculus, M.P.B. and Kattke, K., Entrainment waves in Diesel Jets, SAE Paper No. 2009-01-1355 (2009).

Wakuri, Y., Fujii, M., Amitani, T. and Tsuneya, R., Studies on the penetration of fuel spray of diesel engine, Transactions of the Japan Society of Mechanical Engineers, Vol. 25, No. 156 (1959), pp. 820-826 (in Japanese). 